\title{
As representações sobre o professor de Educação Física nos anos 1970 no Brasil: do desejo à insegurança profissional
}

The representations about the Physical Education teacher in the 1970s in Brazil: the desire to the professional insecurity

Guilherme Gonçalves Baptista

Instituto Federal de Educação, Ciência e Tecnologia do Rio de Janeiro (IFRJ), Brasil

guilherme.baptista@ifrj.edu.br

Juliana Gonçalves Baptista

Instituto de Estudos em Saúde Coletiva, Universidade Federal do Rio de Janeiro, Brasil

\begin{abstract}
Resumo:
Esse artigo objetivou analisar as representações de professores formados pela Escola de Educação Física e Desportos (EEFD) da Universidade Federal do Rio de Janeiro no Brasil na década de 1970 sobre as razões iniciais para a escolha do curso. Foram realizadas entrevistas com quatro ex-alunos da EEFD a partir de um roteiro semiestruturado. Dentre os fatores elencados para justificar a vontade em ingressar na área, destaca-se a presença de um exemplo profissional que marcou a vida escolar dos entrevistados e o gosto por esportes desde a infância. Outro dado relevante foi a ausência de citação sobre o interesse em exercer magistério. Ademais, a ideia de que era uma faculdade associada aos praticantes de atividade física e/ou (ex)atletas era ainda presente ao longo dos anos 1970. Por fim, é caro destacar o aspecto da posição social e as possibilidades econômicas de cada sujeito como itens fundamentais para a construção de representações sobre a área. Embora a imagem da área não fosse um fator de distinção na relação entre os diversos cursos universitários, essa representação se diferenciava na medida em que as possibilidades e ambições dos sujeitos eram postas perante suas condições socioeconômicas.
\end{abstract}

PalaVras-chave: Educação Física, Carreira Docente, Condições Sociais, Representação.

\section{INTRODUÇÃO}

Ao longo da história do campo da Educação Física, a área foi marcada frequentemente pela valorização da técnica e do rendimento (Góis Junior \& Lovisolo, 2003; Soares, 2012). Certamente, esses atributos impactaram de maneira significativa no conjunto de normas, conhecimentos, condutas e práticas a serem ensinadas em um curso superior de Educação Física no decorrer dos anos.

No entanto, antes mesmo da escolha pelo curso, o aluno é marcado por diferentes práticas e discursos. Dentre uma dessas marcas, exaltam-se as formas como o professor de Educação Física é visto em relação a sua profissão na sociedade. Seguramente, essas representações influenciam distintas escolhas, inclusive pela opção ou não em cursar determinada faculdade. Assim, as representações sobre determinada área e seus profissionais igualmente se constituem como um fator significativo para a decisão sobre o caminho a ser trilhado por cada candidato ao Ensino Superior.

Para Alves-Mazotti (1994), as representações sociais ajudam a investigar como se formam e funcionam os sistemas de referência que permitem classificar pessoas e grupos e, a partir disso, analisar como os sujeitos projetam valores e aspirações sociais. Portanto, trata-se de uma atividade representativa na qual os sujeitos em uma mesma condição ou experiência social se servem dos sistemas de códigos e interpretações fornecidos pela sociedade. Em sentido semelhante, Chartier (1991) compreende o conceito de representação como esquemas 
intelectuais que criam figuras devido às quais o presente pode adquirir sentido, o outro tornar-se inteligível e o espaço pode ser compreendido.

É notório que, combinado a esse fator, há inúmeros outros que simultaneamente impactam diretamente na escolha do curso. Para Pinto (2012), a escolha pelo curso é permeada por saberes advindos da família, da escola, do grupo social que, numa relação complexa, dinâmica e persistente, (con)formam representações de mundo em cada indivíduo.

Com isso, o capital simbólico ${ }^{1}$, em forma de prestígio, da Educação Física no período de análise se torna um fator fundamental para compreender essa escolha. Peters (2012), pautado nas contribuiçóes de Bourdieu, define prestígio como a forma assumida pelo capital simbólico em determinado campo que permite o exercício legítimo da autoridade simbólica em um universo social específico. Sob as luzes de Bourdieu $(2011 a)^{2}$, considera-se que o prestígio contribui como um mecanismo de educação do corpo ${ }^{3}$ por levar em conta não somente a representação do campo da Educação Física, a partir de determinados valores e crenças, como também a posição dos sujeitos nesse campo.

Por outro lado, o campo da Educação Física sofreu significativas transformações ao longo da segunda metade do século XX, notadamente a partir dos anos 1970 e 1980. Um processo ambíguo e múltiplo, que culminou na criação de diferentes vertentes pedagógicas para a área (Caparroz, 1993) e num processo de transformação do perfil desse profissional (Baptista, 2019).

Assim, o presente artigo objetiva analisar as representações de professores formados pela Escola de Educação Física e Desportos (EEFD) da Universidade Federal do Rio de Janeiro (UFRJ) no Brasil na década de 1970 sobre as razões iniciais para a escolha do curso.

Trata-se de um dos períodos mais turbulentos na área, denominado inclusive como um momento de crise identitária. Segundo Oliveira (1994), as décadas de 1970 e 1980 constituem um período marcado por constantes conflitos e transformações no campo da Educação Física, no qual havia questionamentos dos valores e normas que eram (re)produzidos. Dentre alguns pontos, Taborda de Oliveira (2001) alerta sobre alguns fatores vigentes nesse momento: a discussão nacional em torno das finalidades da Educação Física brasileira e de seus objetivos no âmbito educacional; a busca por maior reconhecimento social de seus profissionais e por uma identidade "científica"; a tendência de maior influência dos saberes pedagógicos, humanos e sociais no ambiente educacional.

\section{Metodologia}

Para atingir esse objetivo, privilegiou-se a História oral. Esta "consiste na realização de entrevistas gravadas com indivíduos que participaram de, ou testemunharam, acontecimentos e conjunturas do passado e do presente." (Alberti, 2011, p. 155). A escolha desse método se justifica pelas possibilidades de analisar um "caleidoscópio de representações culturais" (Leydesdorf, 2000, p. 75) ao oferecer subsídios para interpretações da mistura cultural que os sujeitos estão imersos e suas respectivas ressignificações.

As fontes orais empregadas foram os depoimentos de quatro ex-alunos da EEFD (P1, P2, P3, P4) na década de 1970 a partir de um roteiro semiestruturado ${ }^{4}$, que participaram do concurso vestibular para ingresso na instituição nesse período. Cabe sinalizar que os entrevistados, além de ex-alunos, são professores da EEFD atualmente. O período da passagem como aluno de cada entrevistado pode ser visto no Quadro 1 abaixo: 
QUADRO 1

Características dos professores entrevistados

\begin{tabular}{|l|l|l|}
\hline Entrevistado & Sexo & $\begin{array}{l}\text { Passagem } \\
\text { como aluno }\end{array}$ \\
\hline P1 & Masculino & $\begin{array}{l}1970 \mathrm{a} \\
1972\end{array}$ \\
\hline P2 & Masculino & $\begin{array}{l}1973 \mathrm{a} \\
1976\end{array}$ \\
\hline P3 & Masculino & $\begin{array}{l}1974 \mathrm{a} \\
1977\end{array}$ \\
\hline P4 & Feminino & $\begin{array}{l}1975 \mathrm{a} \\
1977\end{array}$ \\
\hline
\end{tabular}

Elaborado pelo autor, 2019.

Cabe lembrar, aqui, do historiador Reinhart Koselleck (2011) quando discute as noções de passado, presente e futuro em seu trabalho. Para esse autor, a ideia de presente é resultado da relação entre o que foi vivido e o que se espera do futuro, ou seja, o presente é o encontro do espaço de experiência dos sujeitos e o horizonte de suas expectativas. Igualmente, esse autor alerta que cada presente dá outro significado ao passado e ao futuro, estabelecendo assim uma nova relação entre dois tempos.

Portanto, a escolha do indivíduo para seu futuro profissional está vinculada às experiências vivenciadas e aos significados/sentidos estabelecidos aos eventos por esses sujeitos em determinado tempo histórico. Assim, a memória não foi tratada como verdade absoluta, mas como uma construção e interpretações dos olhos de hoje para outros tempos, aqueles já vivenciados e os que serão ainda percorridos. Em outras palavras, as falas provindas das entrevistas foram tratadas como fonte de pesquisa e cruzadas constantemente com a literatura especializada, notadamente dos estudos historiográficos sobre a área e a EEFD, instituição pretendida pelos depoentes naquele período.

Esclarece-se que essa pesquisa se desenvolveu em consonância com os preceitos éticos para pesquisas com seres humanos, tendo sido aprovado no Comitê de Ética em Pesquisa do Instituto de Saúde Coletiva da Universidade Federal do Rio de Janeiro, processo $n^{\circ}$. 26/2011, respaldado pelo parecer 107/2011.

\section{Resultados E Discuss ̃̃o}

\section{A ESCOLHA PROFISSIONAL: VISÕES E TENSÕES SOBRE A ÁREA}

É caro destacar, inicialmente, que há diversos pontos de vista sobre a Educação Física e não somente de dentro ou de fora desse campo. Deste modo, o (des)prestígio reconhecido da área colabora para subsidiar o confronto entre o desejo de ingressar na faculdade de Educação Física e a perspectiva de futuro almejada pelos alunos a partir da antevisão das possibilidades de acúmulo de capitais com o curso.

Aliás, esse confronto entre o desejo de ingresso e as perspectivas foi visto em todas as falas dos entrevistados. A professora $\mathrm{P} 4$, por exemplo, expõe sua insegurança em explanar para seus familiares e pessoas mais próximas uma decisão que ela mesma já sabia qual seria em relação à faculdade:

Eu desde novinha queria fazer Educação Física, mas naquele tempo, existia uma imagem muito ruim da formação do professor de Educação Física. [...] na época que eu fiz, assim, era uma coisa muito, muito discriminada, quem queria fazer 
Educação Física. Então, eu queria fazer, mas eu sempre ficava com essa inibição de assumir: eu quero ser professora de Educação Física. Então, eu ficava assim: eu quero fazer ou Fisioterapia ou Educação Física ou Psicologia. Ficava nessas três.

A insegurança da escolha pela "imagem ruim" da Educação Física, de certo modo, também foi compartilhada pelo professor P1 ao comentar a sua possibilidade de carreira profissional, as dificuldades vividas e as perspectivas de futuro. O professor, inclusive, define como um momento de crise existencial a troca de opção do curso de Medicina pela Educação Física.

Meu envolvimento, quer dizer, eu queria cursar Medicina em princípio. [...] Mas o fato de eu ter sido atleta e também o fato de eu precisar de dinheiro. De eu não ter (...) minha família ser pobre, de eu precisar trabalhar para me sustentar. Eu fiquei de muito receio de fazer o curso de Medicina que era um curso de horário integral, com o custo alto. Eu estava muito bem no vestibular inclusive, era o meu segundo ano no vestibular. No meu primeiro ano de vestibular coincidiu com ano olímpico. Eu treinei para a Olimpíada, acabei não treinando direito e acabei também não estudando direito. Eu não passei no vestibular para Medicina por meio ponto e não fui para a Olimpíada por um décimo. Não fui bem nos dois. No ano seguinte, eu larguei a natação para estudar mesmo. E quando chegou em setembro, me deu essa crise existencial "caramba, eu acho que não (...)". Eu já estava trabalhando com Natação e tudo.

Por outro lado, o professor P3 destaca sua infância e o papel de um professor como motivadores de sua escolha em cursar a Educação Física posteriormente. Embora também houvesse a Engenharia como opção de faculdade, o professor relata a falta de condições e alternativas devido à situação financeira de sua família naquele momento e sua inclinação para uma área que ele tratava como mais biológica.

Eu tinha também um professor de Educação Física no Ginásio chamado José Rocha. Ele era um entusiasta, um sujeito que o olhinho brilhava quando falava de Educação Física e, no Ginásio, montou uma equipe de Atletismo para competirmos nos campeonatos estaduais, intercolegiais. Eu via a vibração dele, aquele entusiasmo dele e me impregnei muito disso e comecei a achar que queria fazer Educação Física. Tinha um negócio de Engenharia, mas isso não era minha praia. Minha cabeça é científica, mas de outra maneira, mais biológica do que tecnológica. Quando terminei o Ginásio científico, fiz o vestibular e minha família era muito pobre, então não tive alternativa. Ou era fazer Educação Física no Fundão ou fazer Educação Física no Fundão. E eu sempre fui muito chato, sempre que eu quis as coisas fui muito determinado.

Nessa passagem, observa-se como a referência de alguém em uma profissão pode ser tratada como relevante para escolhas futuras na vida de outra pessoa. Além de ter propiciado um espaço para práticas esportivas, o citado professor José Rocha atuou como um “espelho” para o professor P3 diante da sua admiração para com ele e um gosto para a área já evidente do segundo.

De modo similar, a professora $\mathrm{P} 4$ salientou a importância da instituição de ensino na qual estudou e o projeto de Educação Física como itens de impacto em sua escolha futura. Em suas palavras, "Eu estudava no nome da instituição [...] que tinha um projeto de Educação Física fantástico [...] isso me incentivou mais ainda (a fazer Educação Física)".

Nota-se, assim, a interferência do processo de imitação prestigiosa, assinalado por Mauss (2003). Segundo esse autor, "a criança, como o adulto, imita os atos bem-sucedidos que ela viu ser efetuados por pessoas nas quais confia e que têm autoridade sobre ela" (p. 405). Nesse sentido, nota-se como a figura de uma pessoa respeitada colaborou na construção dos valores, dos comportamentos e das escolhas desses sujeitos.

Já o professor P2 relata seu desconhecimento da existência de faculdade de Educação Física até momentos próximos de sua escolha, demonstrando que a área passava ainda por um processo de fortalecimento enquanto faculdade no Ensino Superior. Segundo o docente, foi em uma conversa com o amigo no colégio que tomou ciência da existência do curso e por conta de seu gosto pela área resolveu tentar o vestibular para a área, apesar de não possuir referências positivas de pessoas na área como nos casos anteriores. Nesse item, é importante citar que até o ano de 1974 só existia o curso de Educação Física, no âmbito civil e da cidade do Rio de Janeiro, na UFRJ, embora nos anos subsequentes essa área tenha adquirido um maior espaço e credibilidade no espaço universitário ${ }^{5}$ (Baptista, 2019).

Eu estudava no Ensino Médio, que é o antigo Científico. E estava no segundo ano, entrando na escola, indo para a aula e me lembro que um colega chamado Marcos falou assim? Ah! Alguém vai fazer o curso de Educação Física no Curso Superior. Aí 
eu falei: Ué! Tem curso para Educação Física? Eu não sabia. Fui saber nesse dia e foi nesse dia que eu decidi fazer Educação Física. [...] Quando eu descobri que existia um curso para a Educação Física, eu me identificava muito com a área e para você ter uma ideia, nas aulas de Educação Física dos colégios em que eu estudei, sempre foram colégios públicos, eu tinha uma participação efetiva e me lembro até hoje de cada um deles, os que foram muito bons e os que não foram tão bons. $\mathrm{Na}$ verdade, a maioria foi péssimo! [...] Então, como eu me identificava e descobri que existia um curso superior, eu disse: quero fazer Educação Física.

Apesar de ilustrativo, os depoimentos sobre a aproximação de cada entrevistado com o campo da Educação Física ajudam a visualizar alguns dos diferentes dilemas e acasos enfrentados durante o cotidiano que compõem o momento da escolha de uma carreira profissional. Dentre alguns fatores, foram vistos: a necessidade de ganhar dinheiro, frustrações em outros campos, marcas de experiências anteriores, eventos ocorridos no mesmo período, pessoas marcantes que serviram como exemplo etc..

\section{OS CAPITAIS E AS MARCAS ESPORTIVAS}

Pautado na teoria de reprodução social bourdieusiana, Shilling (2005) cita que os principais fatores interrelacionados que marcam o corpo e influenciam as escolhas dos sujeitos em toda a esfera da vida social são: posição social, habitus e desenvolvimento do gosto. Segundo esse autor, a posição social diz respeito ao volume total de capital possuído pelo sujeito, o relativo peso de seus diferentes bens e a mudança nessas propriedades ao longo do tempo; já habitus é formado no contexto da localização social das pessoas e manifesta uma visão de mundo baseada e conciliada nessas posições, sendo simultaneamente um aspecto estruturado e estruturante no/do seio social; e, por fim, gosto se refere ao processo pelo qual os indivíduos apropriam, como escolhas voluntárias e preferenciais, estilos de vida que são na realidade enraizados em constrangimentos materiais, sendo considerado como uma manifestação consciente do habitus.

Portanto, além desses dilemas e acasos, as distintas maneiras como os agentes buscavam compreender as possibilidades de acúmulo de capitais, a partir de suas posições, seja social ou econômica, também influenciavam a escolha pelo curso de graduação a ser seguido. Essa questão, aliás, pode ser vista claramente na fala dos entrevistados, que por ora exaltavam as dificuldades financeiras, ora sua aproximação com o campo esportivo, entre outros fatores.

Nesse sentido, concorda-se com Huberman (2007) quando afirma que a escolha de uma identidade profissional está associada à renúncia a outras identidades, pelo menos por um determinado período. Isso se dá ao passo que as opções de vida profissional e as possibilidades de acúmulo de capitais simultaneamente são imaginadas pelos ingressantes antes mesmo do início da faculdade. Assim, pode-se considerar que a escolha por um curso de graduação é construída a partir de um emaranhado de fatores que construirão o caminho a ser percorrido.

De maneira geral, observa-se que a Educação Física carecia de um reconhecimento social distintivo frente às outras faculdades no interior das Universidades nesse período, fato já mencionado por Taborda de Oliveira (2001) também. A própria insegurança em assumir tal escolha, o desconhecimento da existência do curso e o alinhamento da ideia de um curso mais viável ou atrativo apenas para pessoas em situações econômicas e sociais mais desfavoráveis ilustram essa interpretação. É importante, no entanto, reconhecer também que a forma como a função da Educação Física era vista e o prestígio que distintos segmentos sociais atribuíam à mesma dependiam de fatores que escapam ao controle total das instituições normatizadoras (Proni, 2010).

Além disso, a própria "imagem ruim" da área frente à parte da sociedade, sobretudo no campo universitário, remonta, de certo modo, a permanência de certa distinção entre o trabalho físico e intelectual, presente até os dias de hoje em nossa sociedade. Aliás, a visão de que era um curso para atleta fomentava a ideia dessa diferenciação. Os depoimentos da professora P4 e do P1, respectivamente, expõem as seguintes descrições: 
[...] era uma coisa muito, muito discriminada. Quem queria fazer Educação Física. [...] sempre ficava com essa inibição de assumir: eu quero ser professora de Educação Física [...] Nós tínhamos nas turmas os atletas das modalidades, os campeões estavam dentro da Escola. Era muito forte essa questão do atleta vindo fazer Educação Física. Muito forte mesmo.

Meu pai dizia que eu ia ser vagabundo. Eu ia ser atleta, atleta e vagabundo eram uma coisa muito parecida para ele.

Ao analisar a sociedade francesa ao longo dos anos 1960 e 1970, Le Breton (2011) afirma que havia uma relação mais instrumental com o corpo das classes populares e, em contrapartida, as classes privilegiadas tendiam a estabelecer uma fronteira mais consciente em favor de suas relações orgânicas e expressões das sensações e em detrimento da força física. Essa interpretação reforça a ideia de Shilling (2005) quando afirma que a posição social e o habitus estão intimamente associados à construção dos gostos e corrobora com Bourdieu (2011b) ${ }^{6}$, que relata que uma prática física/esportiva é mais estimada de acordo com seu alinhamento a certa visão do corpo particular aos agentes de determinada classe social e, simultaneamente, é menos valorizada na medida em que se distancia dessa percepção.

Nesse cenário, a confusão entre a imagem de um atleta e de um professor de Educação Física reforçava a dicotomia físico versus intelectual, uma vez que estabelecia a ideia de que o corpo físico seria um instrumento essencial para essa profissão. A própria exigência de testes de habilidade específica7 como primeira etapa da EEFD para a seleção dos alunos colaborava para promover essa percepção. Portanto, essa ideia de um curso não muito intelectualizado por parte da lógica universitária e, principalmente, de (ex-)atletas, ou, pelo menos, de alunos ligados aos esportes, foram representações presentes no período em questão e, certamente, impactavam na relação entre desejo em fazer um curso e perspectivas de acumulação de capitais.

Aliás, o vínculo do esporte como mais um fator preponderante para a escolha da profissão é outro ponto interessante. A ligação entre esportes e a escolha pela faculdade de Educação Física surgiu em todos os depoimentos, nos quais o gosto e a experiência da prática esportiva foram indicados como causas importantes para essa escolha.

[...] eu era atleta de natação, atleta em nível de seleção brasileira. Nadei Jogos Pan-Americanos em 77. Jogava polo-aquático também. Então, isso me influenciou fortemente para eu abandonar o vestibular de Medicina e fazer o vestibular para Educação Física. (P1)

[...] sempre fui ligado ao esporte, mas de uma forma totalmente informal. [...] Eu fazia parte de um grupo de futebol que me chamava para jogar, eu era um bom goleiro de futsal, então tinha sempre participação. Mas sempre gostei de esporte, mas como o esporte naquela época não era tão fácil, tirando o futebol, de acesso à população e eu não frequentava clubes, eu não praticava esportes. Eu lembro que a primeira vez eu joguei voleibol foi com os meus amigos que jogavam futebol, em uma quadra improvisada e me apresentaram o esporte e eu vi, olha que legal! Eu não tive acesso. Então o acesso ao esporte era mais difícil. Bom, então eu sempre pratiquei... (P2)

No entanto, é pertinente destacar novamente que esse vínculo não era um fator isolado. $\mathrm{O}$ caso do professor P2, por exemplo, chama à atenção sua lembrança não estar vinculada à prática isolada do esporte, mas constantemente ao aspecto da convivência com os amigos. Nesse sentido, a prática esportiva, embora prazerosa por si só, era vista como um momento de reforço dos laços de amizade nesse caso. A satisfação por esses momentos certamente foi incorporado e acabou por marcar seu gosto e escolhas.

O gosto pelo esporte, portanto, delineava uma possível educação do corpo para a Educação Física, constituindo uma ideia de coletivo. Nesse sentido, a experiência de vida esportiva dos candidatos era considerada como um dos principais motivos e justificativas pelo interesse no curso de Educação Física, sendo tratada como um importante símbolo de como a área era representada e como um atributo associado ao perfil do professor da área. Tal ideia, seguramente, contribuía como uma das primeiras formas de educação do corpo para a área ao evidenciar certos valores, como, por exemplo, o gosto pelos esportes.

Em seu trabalho, Pirolo (1996), ao entrevistar professores universitários da disciplina Voleibol, também acentua que muitos deles compreendiam que a experiência esportiva, enquanto jogo e/ou prática desportiva, proporcionou-lhes certa competência, responsável pela escolha do curso de Educação Física e pelas oportunidades que tiveram no mercado de trabalho do ensino superior. Na mesma direção, Pinto (2012) 
salienta que os professores entrevistados em seu estudo creditavam às suas vivências esportivas a construção de um saber prático que os qualificava a iniciar o curso de Educação Física com perspectiva de sucesso na profissão.

Contudo, é pertinente ressaltar que isso não é uma particularidade desse período. Conforme Figueiredo (2004), apesar das mudanças ocorridas na Educação Física, a estreita vinculação entre a área e os esportes, ao longo dos anos, ainda vem sendo uma das principais referências dos alunos que ingressam no curso e, simultaneamente, um entrave por dificultar a compreensão da área em uma dimensão mais ampla e suas diferentes interfaces com outros campos de saberes.

Além da influência das experiências esportivas na escolha pela área, essas vivências igualmente cooperaram para produção de representações das práticas esportivas para a vida desses sujeitos, dado observado também por Pinto (2012) em seu trabalho. A fala do professor P1, por exemplo, ilustra a relação funcionalista do esporte e da preparação para a vida.

Comecei no Botafogo e foi o clube que eu assim (...) Acho que o Botafogo foi a minha segunda família, minha segunda escola. Foi uma escola para mim de vida, o esporte. E me direcionou, me ajudou a decidir à carreira e me ajudou também no início da carreira. Na medida em que comecei a ajudar os professores de forma desinteressada. Eu ficava lá no clube ajudando aos professores nas aulas de aprendizagem de natação porque eram muitas crianças e a piscina era funda. Então, eu ficava transportando as crianças de um lado para o outro. E aquilo eu fui tomando gosto, fui olhando aquele trabalho e fui tomando gosto pela atividade. E quando me vi, eu estava envolvido dando aula.

Aliás, essa relação funcionalista entre Educação Física e contexto social eram bem comum à época, sendo um discurso amplamente propagado durante esse período (Bracht, 1986). De acordo com Taborda de Oliveira (2004), o esporte era visto como uma atividade educativa de excelência. Essa ideia fica representada na fala de P1 a partir da analogia do esporte ser uma "escola de vida" ou uma "segunda casa".

Nota-se, desta maneira, que as experiências esportivas colaboraram para a incorporação de determinados valores, como alguns códigos específicos de uma dada prática esportiva, que estavam associados à escolha por uma faculdade de Educação Física. Porém, a fala do professor P 1 também ilustra como as posições dos agentes e suas experiências eram importantes para a constituição de estratégias capazes de proporcionar algum tipo de acúmulo de capital ao sujeito.

Conforme Bourdieu (2004), os agentes sociais estão inseridos na estrutura e desenvolvem estratégias para modificar as estruturas em razão de suas disposições, visando o acúmulo de capitais. Isso fica evidente ao analisar a interferência em sua escolha pelo fato de já trabalhar com Natação antes mesmo de entrar como aluno para a faculdade e, com isso, visualizar a possibilidade daquela experiência proporcionar um acúmulo de algum tipo de capital posteriormente.

Outro aspecto notado foi a experiência em determinados esportes como um possível elemento influenciador da escolha pelo curso. Os esportes mais citados como aqueles praticados pelos entrevistados ao longo de suas vidas foram: futebol, voleibol, natação e atletismo.

Obviamente, a facilidade ou a condição em praticar determinados esportes influencia em sua escolha para momentos de lazer ou recreação, por exemplo. Portanto, o próprio bairro, região da cidade ou até mesmo a instituição de ensino interferem de maneira decisiva nessas escolhas por conta de suas possibilidades distintas ${ }^{8}$. Isso fica evidente inclusive na fala do professor P3:

Primeira coisa é que eu morava no subúrbio. Tinha espaço livre, não era como hoje cheio de comunidades, eu andava na rua despreocupado. Por não ter essa quantidade de edificação que tem hoje, tinha bastante espaço.

Pinto (2012) também verificou que foram experiências em esportes similares que contribuíram para a escolha de seus entrevistados pelo curso de Educação Física. Aliás, os esportes contidos no currículo da EEFD como disciplina obrigatória eram similares aos citados pelos entrevistados, tais como: Atletismo, Basquetebol, Ginástica Olímpica, Natação, Voleibol, Judô, Futebol, Ginástica Rítmica Desportiva e Handebol (EEFDUFRJ, 1983). Estes esportes eram também as principais atividades oferecidas nas colônias de férias 
promovidas pela EEFD-UFRJ em parceria com outras faculdades ao longo da década de 1970 e perdurando até pelo menos o final dos anos 1980 (EEFD-UFRJ, 1989).

\section{ConClusões}

Ao elencar como objetivo analisar as representações sobre a carreira do professor de Educação Física na década de 1970 pretendeu-se lançar olhares sobre um período reconhecidamente de expansão do curso de Educação Física no Ensino Superior na cidade do Rio de Janeiro e de diferentes transformações nesse campo de conhecimento. Com isso, a análise dos quatro depoimentos nesse estudo foi de significativa importância para compreender alguns dos diferentes fatores que envolviam a escolha da profissão de professor de Educação Física em distintas perspectivas.

Nesse contexto, notou-se que todos os entrevistados passaram por momentos de confronto entre o desejo de ingressar na faculdade de Educação Física e a expectativa de seu futuro. Nesse confronto, não só suas representações eram postas, mas também de seus familiares e amigos mais próximos, que incentivavam ou desestimulavam esses sujeitos a partir de suas representações sobre a área.

Aliás, um dos fatores elencados para justificar a vontade em ingressar na área foi a figura de um profissional ou um projeto de Educação Física respeitado por eles ao longo de sua vida escolar. Em outras palavras, a admiração e respeito por essas pessoas e suas práticas se transformaram em um estímulo para ingressar na área, algo bem próximo do que Marcel Mauss (2003) definiu como o fenômeno da imitação prestigiosa.

No que se refere às representações sobre a área, pode-se observar que a ideia de que era uma faculdade associada aos praticantes de atividade física e/ou (ex)atletas era ainda bastante presente na imagem sobre o profissional da área na década de 1970. Ao detalhar sua aproximação com o campo da Educação Física, apenas um entrevistado cita o gosto por ajudar um professor da área como motivador de sua escolha. Os demais relatam suas experiências e gostos esportivos, o que demonstrava ainda o distanciamento da figura profissional do professor de Educação Física com a ideia do magistério nas representações sobre a área.

Inclusive, o gosto por alguns esportes foi um dos principais atrativos para a escolha do curso. Os esportes, igualmente, foram tratados recorrentemente como um instrumento pedagógico que colaborou para a construção de determinados valores e crenças para a vida desses sujeitos. Nessa interpretação, o esporte era uma "segunda escola", embora não houvesse uma visão crítica sobre como esse instrumento era tratado.

Por fim, é caro destacar o aspecto da posição social e as possibilidades econômicas de cada sujeito como item fundamental para a construção de representações sobre a área. Embora a imagem da área não fosse um atrativo e um fator de distinção dentro da lógica das profissões certificadas por cursos universitários, essa representação entre os depoentes se diferenciou na medida em que suas possibilidades e ambições eram postas em jogo diante de suas condições socioeconômicas.

Além do mais, verificou-se que as próprias ambições dos sujeitos foram (con)formadas ao longo de suas vidas mediante à incorporação de certos valores, dificuldades e expectativas, que logicamente eram marcadas pelas posições e condições sociais. Assim, a escolha pela faculdade de Educação Física pode ter trazido uma insegurança para alguns sujeitos diante de sua imagem "ruim" de um curso pouco intelectualizado no campo universitário, por outro lado, foi tratada como uma possibilidade real de transformação do status quo dos sujeitos a partir de seu ingresso em uma instituição do Ensino Superior, seja pública ou privada.

\section{REFERÊNCIAS}

Alberti V. (2011) Histórias dentro da História (3a ed.). In: Pinsky C. B. (org.). Fontes Históricas (155 - 202). São Paulo, Brasil: Contexto.

Alves-Mazzotti A. J. (1994). Representações Sociais: aspectos teóricos e aplicações à Educação. Em Aberto, 14(61), 60-78. 
Baptista G., G.; Lüdorf S. M. A. (2016). "Educação do corpo": a leitura de uma agenda em construção. Movimento, 22(3), 723-738.

Baptista G., G.(2019). As marcas de um campo em debate: Os testes de Aptidão Física na Escola de Educação Física e Desportos-UFRJ (1968-1990). (Tese de doutoramento). Faculdade de Educação - Universidade Federal do Rio de Janeiro. Rio de Janeiro, Brasil.

Bourdieu P. (2004). Os usos sociais da ciência:por uma sociologia clínica do campo científico. [Denice Catani: tradução]. São Paulo, Brasil: Editora UNESP.

Bourdieu P. (2011a). O poder simbólico (15ª ed.). [Fernando Tomaz: tradução]. Rio de Janeiro, Brasil: Bertrand Brasil.

Bourdieu P. (2011b). A distinção: crítica social do julgamento (2a ed.). [Daniela Kern; Guilherme Teixeira: tradução]. Porto Alegre, Brasil: Zouk.

Bracht V. (1986). A criança que pratica esportes respeita as regras do jogo... capitalista. Revista Brasileira de Ciências do Esporte, 7(2), 62-68.

Caparroz F. E. (1993). Órfăos dos anos 80? Revista Brasileira de Ciências do Esporte, 14(2), 91-92.

Chartier R. (1991). O mundo como representação. Estudos Avançados, 5(11), 173-191.

Figueiredo Z. C. C. (2004). Formação docente em Educação Física: experiências sociais e relação com o saber. Movimento, 10(1), 89-111.

Gaskell G. (2003). Entrevistas individuais e grupais (2a ed.). In: Bauer M. W.; Gaskell G. (Orgs.) Pesquisa qualitativa com texto: imagem e som, um manual (64 - 98). [Pedrinho A. Guareschi: tradução]. Petrópolis, Brasil: Vozes.

Góis Junior E.; Lovisolo H. R. (2003). Descontinuidades e continuidades do movimento higienista no Brasil. Revista Brasileira de Ciências do Esporte, 25(1), 41-54.

Huberman M. (2007) O ciclo de vida profissional dos professores ( $2^{a}$ ed.). In: Nóvoa A. (Org.). Vida de professores. (31 - 61) Porto, Portugal: Porto Editora.

Koselleck R.(2011) Futuro passado: contribuição à semântica dos tempos históricos (2a ed.). [Wilma Patrícia Maas; Carlos Almeida Pereira: tradução]. Rio de Janeiro, Brasil: Contraponto.

Le Breton D. (2011) Antropologia do corpo e Modernidade. [Fábio dos Santos Creder Lopes: tradução]. Petrópolis, Brasil: Vozes.

Leydesdorf S. (2000) Desafios do transculturalismo. In: Alberti V.; Fernandes T. M.; Ferreira M. M. (orgs). História oral: desafios para o século XXI (73 - 84). Rio de Janeiro, Brasil: Editora Fiocruz.

Mauss M. (2003) As Técnicas Corporais. In: Mauss M. Sociologia e Antropologia, São Paulo, Brasil: Cosac \& Naify.

Oliveira V. M. (1994). Consenso e conflito da Educação Física brasileira. Campinas, Brasil: Papirus.

Peters G. (2012). O social entre o céu e o inferno: a antropologia filosófica de Pierre Bourdieu. Tempo Social, 24(1), $229-261$.

Pinto J. F. (2012). Memórias de professores/as de Educação física sobre formação e Práticas Pedagógicas (1950 a 1970). (Tese de doutoramento). Universidade Federal de Minas Gerais. Minas Gerais, Brasil.

Pirolo A. L. (1996) A Disciplina Voleibol nos Cursos de Licenciatura em Educação Física do Estado do Paraná: processo de conhecimento crítico-reflexivo? (Dissertação de Mestrado). Universidade Gama Filho. Rio de Janeiro, Brasil.

Proni M. W. (2010) Universidade, profissão Educação Física e o mercado de trabalho. Motriz, 16(3), 788-798.

Shilling C. (2005) The body and social theory. (2a ed). Londres, Inglaterra: Sage Publications.

Soares C. L. (2012) Educação Física: raízes europeias e Brasil. (5a ed.). Campinas, Brasil: Autores Associados.

Taborda de Oliveira M. A. (2001). A Revista Brasileira de Educação Física e Desportos (1968-1984) e a experiência cotidiana de professores da rede municipal de ensino de Curitiba: entre a adesão e a resistência. (Tese de doutoramento). Pontifícia Universidade Católica de São Paulo. São Paulo, Brasil.

Taborda de Oliveira M. A. (2004). Educação Física escolar e Ditadura militar no Brasil (1968-1984): entre a adesão e a resistência. Revista Brasileira de Ciências do Esporte, 25(2), 9-20.

Universidade Federal do Rio de Janeiro. Currículo da EEFD-UFRJ. Arquivo do Centro de Memória da EEFD, 1983. 
Universidade Federal do Rio de Janeiro. Projetos da extensão da EEFD-UFRJ. Arquivo do Centro de Memória da EEFD, sd/1989.

Universidade Federal do Rio de Janeiro. EEFD. Ofício Circular da Área de Ensino de Graduação e Corpo Discente. Arquivo do Centro de Memória da EEFD, s/d.

\section{Notas}

1 Bourdieu (2011) define capital como a representação de um poder sobre um universo específico em determinado momento, demarcando as probabilidades de ganhos de seu detentor nesse espaço.

2 A primeira edição do livro "O Poder Simbólico" é do ano de 1989.

3 processo de normatização marcado por discursos de poder que transpassam o corpo na tentativa de (con)formar os indivíduos por meio de suas carnes, suas sensibilidades e/ou seus espíritos.

4 De acordo com Gaskell (2003), o roteiro deve ser usado com alguma flexibilidade em uma entrevista qualitativa, servindo muito mais como um guia para aprofundar questões essenciais da pesquisa ao invés de escravizar o entrevistador em torno dele.

5 Conforme o Ofício da Área de Ensino de Graduação e Corpo Discente (s/d), a relação de candidato/vaga para o curso de Licenciatura em Educação Física na UFRJ em 1982 era de 10,35.

6 A primeira edição brasileira do livro "A distinção: crítica social do julgamento" é ano de 2006.

7 Os testes em uma bateria de exercícios voltados para verificar alguns parâmetros para o ingresso dos alunos nos cursos de Educação Física.

8 É importante mencionar que todos os entrevistados eram residentes da cidade do Rio de Janeiro na década de 1970, mais especificamente na zona Norte. 